\title{
Influence of Postoperative Pneumonia on Esophageal Cancer Survival and Recurrence
}

\author{
AYAKO TAMAGAWA*, TORU AOYAMA*, HIROSHI TAMAGAWA, MIHWA JU, KEISUKE KOMORI, \\ YUKIO MAEZAWA, KAZUKI KANO, KEISUKE KAZAMA, MASAAKI MURAKAWA, \\ YOSUKE ATSUMI, SHO SAWAZAKI, KENTARO HARA, MASAKATSU NUMATA, \\ TSUTOMU SATO, NORIO YUKAWA, MUNETAKA MASUDA and YASUSHI RINO
}

Department of Surgery, Yokohama City University, Fukuura, Kanazawa, Japan

\begin{abstract}
Background/Aim: Postoperative pneumonia after esophageal cancer can lead to additional pain, prolonged hospital stay, and respiratory failure. These adverse events might lead to early recurrence and/or death. We investigated the influence of postoperative pneumonia on the esophageal cancer survival and recurrence after curative surgery. Patients and Methods: This study included 122 patients who underwent curative surgery for esophageal cancer between 2008 and 2018. The patients were classified into: i) those with postoperative pneumonia (pneumonia group) and ii) those without postoperative pneumonia (non-pneumonia group). The risk factors for the overall survival (OS) and recurrence-free survival (RFS) were identified. The rate of postoperative pneumonia was measured by the revised Uniform Pneumonia Score. Results: Postoperative complications were found in 34 of the 122 patients (27.9\%). The OS rate at 5 years following surgery was $28.2 \%$ in the pneumonia group and $55.1 \%$ in the non-pneumonia group $(p=0.006)$. The RFS rate at 5 years after surgery was $18.9 \%$ in the pneumonia group and $49.2 \%$ in the non-pneumonia group $(p=0.061)$. A multivariate analysis showed that postoperative pneumonia was a significant independent risk factor for OS. Conclusion: The development of postoperative pneumonia was a risk factor for a decreased overall survival in patients who underwent curative surgery for esophageal cancer. The surgical procedure, perioperative care and surgical strategy should be carefully planned in order to avoid postoperative pneumonia.
\end{abstract}

*These Authors contributed equally to this study.

Correspondence to: Toru Aoyama, Department of Surgery, Yokohama City University, 3-9 Fukuura, Kanazawa-ku, Yokohama 236-0004, Japan. Tel: +81 457872800, e-mail: t-aoyama@lilac.plala.or.jp

Key Words: Esophageal cancer, postoperative pneumonia, overall survival, recurrence.
Esophageal cancer is the eighth-most common cancer in the world and the sixth-most common cause of death due to cancer (1). More than 450,000 new esophageal cancer diagnoses and more than 400,000 deaths per year were reported in 2012 worldwide. Complete resection is essential for curing esophageal cancer $(2,3)$, however, although the resection rate has gradually increased, patients with esophageal cancer often develop tumor recurrence even after complete curative resection. Therefore, it is important to identify reliable predictive factors for patients at high risk of recurrence.

Recent studies have shown that the development of postoperative complications decreases patients' survival or increases the risk of disease recurrence in various types of malignancies (4-7). Esophageal cancer surgery frequently causes postoperative complications (in 20-60\% of cases), which might be one reason for the poor survival (8-11). Among the postoperative surgical complications, postoperative pneumonia is a major complication following esophagectomy, and rates have been reported to range from $20-40 \%$ (11-13). Postoperative pneumonia can lead to additional pain, prolonged hospital stay, and respiratory failure. These adverse events might lead to early recurrence and/or death.

We hypothesized that postoperative pneumonia has some clinical influence on the overall survival (OS) and/or recurrence in esophageal cancer patients who receive curative resection. To test our hypothesis, we evaluated whether or not the OS and recurrence-free survival (RFS) were shortened by the development of postoperative pneumonia in patients who underwent curative resection for esophageal cancer.

\section{Patients and Methods}

Patient data. Our study cohort was selected from medical records to be consecutive patients who underwent esophagectomy for esophageal cancer at Yokohama City University from January 2005 to September 2018. The patients met the following inclusion criteria: i) histologically proven primary esophageal squamous cell carcinoma, ii) clinical stage IB to III (excluding T4) disease, as 
evaluated using the 7th edition of the tumor-node-metastasis classification established by the Union for International Cancer Control (UICC) (14), and iii) complete (R0) resection of the esophageal cancer with radical lymph node dissection. Patients who had undergone R2 or R1 resection were excluded from the study.

Surgical procedure. Our standard procedures consisted of open subtotal esophagectomy via right thoracotomy, reconstruction with a gastric tube through the posterior mediastinal route or retrosternal route, and anastomosis in the cervical incision. In principle, twofield lymph node dissection is indicated when tumors are located at the middle thoracic to lower thoracic esophagus, while three-field dissection is applied for upper thoracic tumors. A feeding tube was routinely placed at the stomach or duodenum.

Perioperative care. All of the patients received the same perioperative management. Antibiotics were administered 30 minutes before surgical incision and then again every 3 hours during surgery as well as on postoperative day (POD) 2 . The patients were allowed to eat $30 \%$ rice porridge until midnight the day before the surgery. The patients remained on ventilation overnight. Ambulation and enteral nutrition started on POD 1. Oral intake was initiated on POD 5, beginning with water and gelatinous foods. The patients began to eat solid food on POD 10, starting with rice gruel and soft food and progressing in three steps to regular food intake.

Definition of postoperative pneumonia. All data were retrospectively retrieved from the patients' records. The rate of postoperative pneumonia was measured using the revised Uniform Pneumonia Score (15). This scoring system uses the variables: i) temperature, ii) leucocyte count, and iii) chest X-ray findings, to determine whether or not treatment of pneumonia is indicated (Table I) $(16,17)$. Chest $\mathrm{X}$-ray was performed according to unstandardized local routine care policies. On the days when chest X-ray was performed, the local researcher assessed the variables of the Uniform Pneumonia Score.

Follow-up. In principal, the patients were followed-up at outpatient clinics. The follow-up program of postoperative surveillance principally consisted of: i) a physical examination, ii) blood chemistry assessments, including SCC tumor markers, every three months for the first year and every six months thereafter, and iii) computed tomography of the neck, chest, and abdomen every six months. Disease recurrence was diagnosed based on radiographic evidence of a new suspicious low-density mass in the region of the mediastinum, lymph nodes, liver, lung, or at other distant sites.

Evaluations and statistical analyses. The OS was defined as the period between the date of surgery and death. The RFS was defined as the period between surgery and the occurrence of an event, recurrence or death, whichever came first. The data of patients who had not experienced an event were censored at the date of the final observation. The OS and RFS curves were calculated using the Kaplan-Meier method and were compared using the log-rank test. The Cox proportional hazards model was used for the univariate and multivariate survival analyses to identify prognosticators. An unpaired Student's $t$-test or the chi-squared method was used to compare the two groups, with $p$-values of $<0.05$ considered statistically significant. The survival data were obtained from hospital records. The SPSS software program (v11.0J Win, SPSS, Chicago, IL, USA) was used to perform all statistical analyses.
Table I. Revised uniform pneumonia score.

\begin{tabular}{lcc}
\hline Diagnostic parameter & Value & Score \\
\hline Temperature $\left({ }^{\circ} \mathrm{C}\right)$ & $\geq 36.1$ and $\leq 38.4$ & 0 \\
& $\leq 36.0$ and $\geq 38.5$ & 1 \\
Leucocyte count $\left(\times 10^{9} / \mathrm{L}\right)$ & $\geq 4.0$ and $\leq 11.0$ & 0 \\
& $<4.0$ and $>11.0$ & 1 \\
Pulmonary radiography & No infiltrate & 0 \\
& Diffused infiltrate & 1 \\
& Well circumscribed infiltrate & 2 \\
\hline
\end{tabular}

Ethics. The present study was conducted in compliance with the 'ethical guidelines for clinical research' (18). This study was approved by the Institutional Review Board (IRB) of the Yokohama City University. Informed consent for using clinical data without identifying personal information was obtained before surgery from all patients.

\section{Results}

Patient characteristics. A total of 122 patients underwent esophagectomy for esophageal cancer between October 2008 and September 2018. The patients' ages ranged from 40 to 82 years (median: 68 years); 106 patients were male, and 16 were female. The median follow-up period was 72.5 months (13.9125.2 months). Thirty-four patients were categorized as those with postoperative pneumonia (pneumonia group), and 88 were categorized as those without postoperative pneumonia (nonpneumonia group). The patient characteristics are summarized in Table II. The relationship between the occurrence of postoperative pneumonia and clinicopathological parameters are shown in Table II. The patient's age, gender, and clinical lymph node metastasis status were associated with the incidence of postoperative pneumonia.

Survival analyses. The OS rates at 3 and 5 years following surgery were $33.8 \%$ and $28.2 \%$ in the pneumonia group patients, respectively, and $65.8 \%$ and $57.4 \%$ in the nonpneumonia group patients, respectively, which were significantly different $(p=0.002)$. The OS curves are shown in Figure 1. Univariate analyses for the OS showed that postoperative pneumonia was a significant prognostic factor, as were the depth of tumor invasion, lymph node status, and lymph vascular invasion (Table III). Postoperative pneumonia was selected for the final model to be analyzed by a multivariate analysis.

The RFS rates at 3 and 5 years following surgery were $28.3 \%$ and $18.7 \%$ in the pneumonia group patients, respectively, and $56.3 \%$ and $49.2 \%$ in the non-pneumonia group patients, respectively, which were marginally significantly different $(p=0.061)$. The RFS curves are shown in Figure 2. Univariate analyses for the RFS showed that 
Table II. Clinicopathological data.

\begin{tabular}{|c|c|c|c|c|c|c|c|}
\hline \multirow[b]{3}{*}{ Characteristics } & \multicolumn{7}{|c|}{ Postoperative pneumonia } \\
\hline & \multicolumn{2}{|c|}{ All cases } & \multicolumn{2}{|c|}{ No $(n=88)$} & \multicolumn{2}{|c|}{ Yes $(n=34)$} & \multirow[b]{2}{*}{$p$-Value } \\
\hline & Number & $\%$ & Number & $\%$ & Number & $\%$ & \\
\hline Age (year) & & & & & & & 0.013 \\
\hline$\leq 68$ & 65 & 53.3 & 53 & 60.2 & 12 & 35.3 & \\
\hline$>68$ & 57 & 46.7 & 35 & 39.8 & 22 & 64.7 & \\
\hline Gender & & & & & & & 0.039 \\
\hline Male & 106 & 86.9 & 73 & 83.0 & 33 & 97.1 & \\
\hline Female & 16 & 13.1 & 15 & 17.0 & 1 & 2.9 & \\
\hline Site of tumor & & & & & & & 0.314 \\
\hline Upper thoracic & 36 & 29.5 & 29 & 33.0 & 7 & 20.6 & \\
\hline Middle thoracic & 56 & 45.9 & 37 & 42.0 & 19 & 55.9 & \\
\hline Lower thoracic & 30 & 24.6 & 22 & 25.0 & 8 & 23.5 & \\
\hline Pathological depth of invasion & & & & & & & 0.741 \\
\hline $\mathrm{T} 1$ & 43 & 35.2 & 32 & 36.4 & 11 & 32.4 & \\
\hline $\mathrm{T} 2-\mathrm{T} 4$ & 79 & 64.8 & 56 & 63.6 & 23 & 67.6 & \\
\hline Pathological lymph node status & & & & & & & 0.003 \\
\hline Negative & 62 & 50.8 & 52 & 59.1 & 10 & 29.4 & \\
\hline Positive & 60 & 49.2 & 36 & 40.9 & 24 & 70.6 & \\
\hline Lymph vascular invasion & & & & & & & 0.259 \\
\hline Negative & 38 & 31.1 & 30 & 34.1 & 8 & 23.5 & \\
\hline Positive & 84 & 68.9 & 58 & 65.9 & 26 & 76.5 & \\
\hline Lymph node dissection & & & & & & & 0.708 \\
\hline Two-field & 75 & 61.5 & 55 & 62.5 & 20 & 58.8 & \\
\hline Three-field & 47 & 38.5 & 33 & 37.5 & 14 & 41.2 & \\
\hline Neoadjuvant chemotherapy & & & & & & & 0.464 \\
\hline Yes & 51 & 41.8 & 35 & 39.8 & 16 & 47.1 & \\
\hline No & 71 & 58.2 & 53 & 60.2 & 18 & 52.9 & \\
\hline
\end{tabular}

postoperative pneumonia was a significant prognostic factor, as were the depth of tumor invasion, lymph node status, and lymph vascular invasion (Table IV). However, postoperative pneumonia was not selected for the final model to be analyzed by multivariate analysis.

Recurrence pattern and causes of death. Regarding the sites of first relapse, some patients had a first relapse at more than one sites, however, there were no significant differences between the patients with and without pneumonia (Table V). The cause of death was analyzed for all patients. The rate of esophageal-cancer-related death was similar between the patients with and without pneumonia ( $81.0 \%$ versus $89.2 \%$ ). The rate of death due to other causes was slightly higher in patients with pneumonia compared to those without pneumonia ( $19.0 \%$ vs. $10.8 \%)$.

\section{Discussion}

The aim of the present study was to evaluate whether or not the OS and RFS were shortened by the development of postoperative pneumonia in patients who underwent curative resection for esophageal cancer. Our major findings show that: i) postoperative pneumonia was observed in almost $30 \%$ of patients following esophageal cancer surgery and ii) was an independent prognostic factor for the OS. To improve the survival among esophageal cancer patients, it is necessary to prevent them from developing postoperative pneumonia following esophageal cancer surgery.

We found a significant difference in OS between patients with and without postoperative pneumonia. Only few reports have described the relationship between postoperative pneumonia and the survival in patients who have undergone esophageal cancer surgery $(15,16)$. For example, Kataoka et al. have evaluated the clinical influence of infectious complications, such as postoperative pneumonia, and leakage in patients who have gone under preoperative chemotherapy, followed by surgery for clinical stage II/III esophageal cancer, using data from a randomized controlled trial (JCOG9907) (19). In the present study, postoperative pneumonia was observed in $30 \%$ of patients. The OS of the patients with pneumonia was shorter compared to those without pneumonia [hazard ratio $(\mathrm{HR})=1.52,95 \%$ confidence interval $(95 \% \mathrm{CI})=1.00-2.31, p=0.048)$. The OS rate at 3 years after 
Table III. Uni- and multivariate Cox proportional hazards analysis of the relationship between clinicopathological factors and overall survival.

\begin{tabular}{|c|c|c|c|c|c|c|c|}
\hline \multirow[t]{2}{*}{ Characteristics } & \multirow[t]{2}{*}{ Number } & \multicolumn{3}{|c|}{ Univariate analysis } & \multicolumn{3}{|c|}{ Multivariate analysis } \\
\hline & & HR & $95 \% \mathrm{CI}$ & $p$-Value & HR & $95 \% \mathrm{CI}$ & $p$-Value \\
\hline Age & & & & 0.121 & & & \\
\hline$<68$ year & 65 & 1.000 & & & & & \\
\hline$\geq 68$ year & 57 & 1.507 & $0.898-2.529$ & & & & \\
\hline Gender & & & & 0.139 & & & \\
\hline Female & 16 & 1.000 & & & & & \\
\hline Male & 106 & 2.153 & $0.780-5.949$ & & & & \\
\hline Site of tumor & & & & 0.392 & & & \\
\hline Lower-Middle thoracic & 86 & 1.000 & & & & & \\
\hline Upper thoracic & 36 & 1.331 & $0.691-2.564$ & & & & \\
\hline Pathological depth of invasion & & & & 0.006 & & & 0.011 \\
\hline $\mathrm{T} 1$ & 43 & 1.000 & & & 1.000 & & \\
\hline $\mathrm{T} 2 / \mathrm{T} 3$ & 79 & 2.387 & $1.286-4.430$ & & 2.243 & $1.206-4.170$ & \\
\hline Pathological lymph node status & & & & 0.019 & & & \\
\hline Negative & 62 & 1.000 & & & & & \\
\hline Positive & 60 & 1.885 & $1.111-3.196$ & & & & \\
\hline Lymph vascular invasion & & & & 0.020 & & & \\
\hline Negative & 38 & 1.000 & & & & & \\
\hline Positive & 84 & 2.182 & $1.131-4.210$ & & & & \\
\hline Postoperative pneumonia & & & & 0.002 & & & 0.006 \\
\hline No & 88 & 1.000 & & & 1.000 & & \\
\hline Yes & 34 & 2.304 & $1.344-3.950$ & & 2.146 & $1.250-3.684$ & \\
\hline Neoadjuvant chemotherapy & & & & 0.881 & & & \\
\hline No & 71 & 1.000 & & & & & \\
\hline Yes & 51 & 1.041 & $0.612-1.771$ & & & & \\
\hline
\end{tabular}

surgery was $59.1 \%$ in the pneumonia group and $66.0 \%$ in the non-pneumonia group. The RFS also tended to be shorter in patients with pneumonia than in those without it $(\mathrm{HR}=1.39$, $95 \% \mathrm{CI}=0.93-2.07, p=0.10)$. The RFS rate at 3 years after surgery was $40.9 \%$ in the pneumonia group and $53.7 \%$ in the non-pneumonia group. In addition, Booka et al. have evaluated the prognostic influence of postoperative pneumonia in 284 esophageal cancer patients who underwent esophagectomy (20). In that study, among the total 284 patients, $64(22.5 \%)$ developed pneumonia following surgery. When comparing the OS of patients according to the pneumonia status, significant differences were noted. Indeed, the OS rates at 1 and 5 years following surgery were $76.6 \%$ and $40.6 \%$ in the pneumonia group, respectively, and $85.5 \%$ and $52.3 \%$ in the nonpneumonia group, respectively. Furthermore, the univariate and multivariate analyses showed that pneumonia was a significant prognostic factor for the OS $(\mathrm{HR}=1.456,95 \% \mathrm{CI}=1.020-2.079$, $p=0.039)$. In contrast, no marked differences in the RFS were noted depending to the pneumonia status.

There are several possible reasons why postoperative pneumonia affects the long-term outcome of esophageal cancer patients. For example, patients who developed postoperative pneumonia may have affected pathways that led to decreased host immunity against the tumor (21-23). However, the detailed mechanism is unclear at present.
Although postoperative pneumonia did have some clinical influence on the OS, neither the present study nor the previous two studies have found any significant clinical influence of this factor on RFS. This discrepancy suggests that postoperative pneumonia might be associated not only with cancer-related death but also with increased risk of noncancer-related death. In the present study, the rate of death due to other causes was slightly higher in patients with pneumonia compared to those without pneumonia. Therefore, postoperative pneumonia might have some clinical influence on death unrelated to esophageal cancer. Similar trends have been observed in previous studies. For example, in Booka's study, in the pneumonia group, $79.1 \%$ of patients died of causes related to esophageal cancer, while $20.9 \%$ died of causes unrelated to esophageal cancer (22). In contrast, in the non-pneumonia group, $88.0 \%$ of patients died of causes related to esophageal cancer, while $12.0 \%$ died of causes unrelated to esophageal cancer. This marginal significance might become more important if the number of patients increases or with a long-term follow-up.

In the present study, we defined postoperative pneumonia based on the revised Uniform Pneumonia Score and diagnosed almost $30 \%$ of patients with postoperative pneumonia. However, the rate of postoperative pneumonia has ranged widely in previous studies. Although patients' background 
Table IV. Uni- and multivariate Cox proportional hazards analysis of the relationship between clinicopathological factors and recurrence-free survival.

\begin{tabular}{|c|c|c|c|c|c|c|c|}
\hline \multirow[t]{2}{*}{ Characteristics } & \multirow[t]{2}{*}{ Number $(\%)$} & \multicolumn{3}{|c|}{ Univariate analysis } & \multicolumn{3}{|c|}{ Multivariate analysis } \\
\hline & & HR & $95 \% \mathrm{CI}$ & $p$-Value & HR & $95 \% \mathrm{CI}$ & $p$-Value \\
\hline Age & & & & 0.742 & & & \\
\hline$<68$ year & 65 & 1.000 & & & & & \\
\hline$\geq 68$ year & 57 & 1.091 & $0.651-1.828$ & & & & \\
\hline Gender & & & & 0.282 & & & \\
\hline Female & 16 & 1.000 & & & & & \\
\hline Male & 106 & 1.590 & $0.683-3.702$ & & & & \\
\hline Site of tumor & & & & 0.853 & & & \\
\hline Lower-Middle thoracic & 86 & 1.000 & & & & & \\
\hline Upper thoracic & 36 & 1.032 & $0.737-1.447$ & & & & \\
\hline Pathological depth of invasion & & & & $<0.001$ & & & $<0.001$ \\
\hline $\mathrm{T} 1$ & 43 & 1.000 & & & 1.000 & & \\
\hline $\mathrm{T} 2 / \mathrm{T} 3$ & 79 & 4.623 & $2.265-9.434$ & & 3.765 & $1.801-7.783$ & \\
\hline Pathological lymph node status & & & & $<0.001$ & & & 0.029 \\
\hline Negative & 62 & 1.000 & & & 1.000 & & \\
\hline Positive & 60 & 2.664 & $1.546-4.590$ & & 1.873 & $1.066-3.291$ & \\
\hline Lymph vascular invasion & & & & 0.005 & & & \\
\hline Negative & 38 & 1.000 & & & & & \\
\hline Positive & 84 & 2.588 & $1.341-4.995$ & & & & \\
\hline Postoperative pneumonia & & & & 0.029 & & & \\
\hline No & 88 & 1.000 & & & & & \\
\hline Yes & 34 & 1.838 & $1.063-3.180$ & & & & \\
\hline Neoadjuvant chemotherapy & & & & 0.089 & & & \\
\hline Yes & 71 & 1.000 & & & & & \\
\hline No & 51 & 1.620 & $0.928-2.827$ & & & & \\
\hline
\end{tabular}

Table V. Patterns of recurrence between the patients with postoperative pneumonia and those without postoperative pneumonia.

\begin{tabular}{|c|c|c|c|c|c|c|c|}
\hline \multirow[b]{3}{*}{ Recurrence site } & \multicolumn{7}{|c|}{ Postoperative pneumonia } \\
\hline & \multicolumn{2}{|c|}{ All cases } & \multicolumn{2}{|c|}{ No $(n=88)$} & \multicolumn{2}{|c|}{ Yes $(n=34)$} & \multirow[b]{2}{*}{$p$-Value } \\
\hline & Number & $\%$ & Number & $\%$ & Number & $\%$ & \\
\hline \multicolumn{8}{|l|}{ Lymph node } \\
\hline Regional & 23 & 18.9 & 15 & 17.0 & 8 & 23.5 & 0.412 \\
\hline Distant & 7 & 5.7 & 4 & 4.5 & 3 & 8.9 & 0.362 \\
\hline Local site & 12 & 9.8 & 8 & 9.1 & 4 & 11.8 & 0.657 \\
\hline \multicolumn{8}{|l|}{ Distant site } \\
\hline Lung & 12 & 9.8 & 8 & 9.1 & 4 & 11.8 & 0.657 \\
\hline Liver & 11 & 9.0 & 8 & 9.1 & 3 & 8.9 & 0.963 \\
\hline Bone & 5 & 4.1 & 5 & 5.7 & 0 & 0 & 0.156 \\
\hline Others & 9 & 8.0 & 6 & 6.8 & 3 & 8.9 & 0.704 \\
\hline Disseminated & 3 & 2.5 & 2 & 2.3 & 1 & 2.9 & 0.831 \\
\hline
\end{tabular}

characteristics, surgical procedure, and postoperative care might influence the incidence of postoperative pneumonia, the lack of a standardized definition of postoperative pneumonia has certainly not helped matters. The present and previous studies lack a consensus regarding the appropriate cut-off points and definitions for the evaluation of the postoperative pneumonia $(12,13,20)$. Postoperative pneumonia in the present study was reported by individual physicians and was not based on a specific protocol. As such, the rate of postoperative pneumonia might have been under- or 


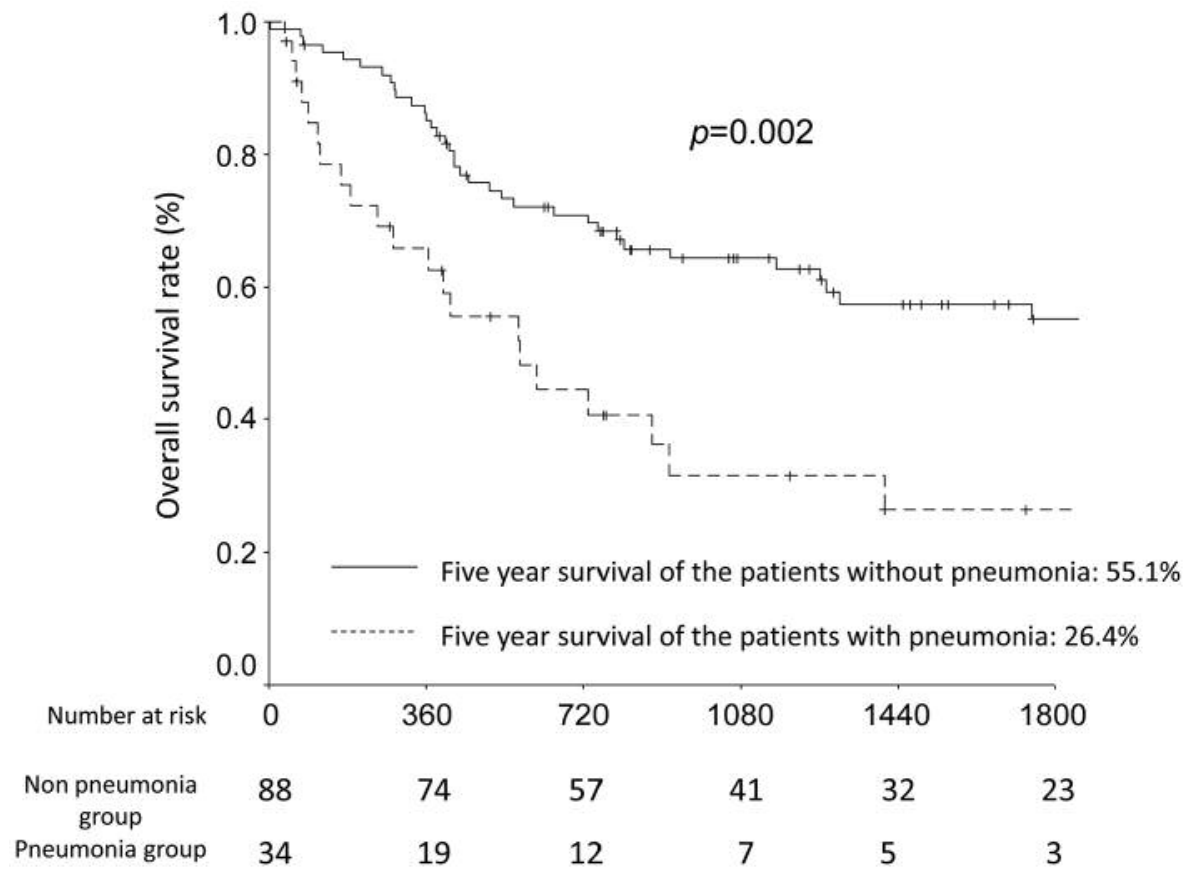

Figure 1. The overall survival curves of patients with and without postoperative pneumonia.

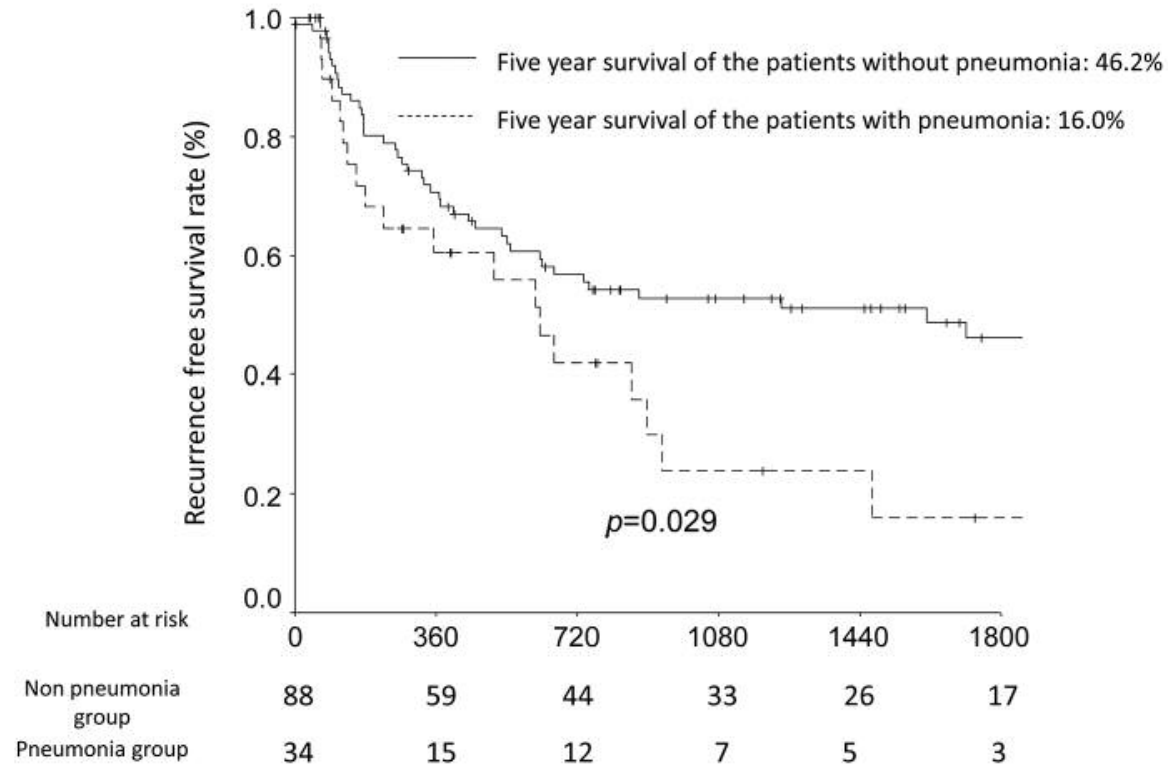

Figure 2. The recurrence-free survival curves of patients with and without postoperative pneumonia.

overestimated. Future studies should focus on how to best define and diagnose postoperative pneumonia.

Special attention is required when interpreting the current results, as there are some potential limitations associated with this study. First, this was a retrospective, single-center study with a small sample size. Our findings may, therefore, have been observed merely by chance in this series. Second, there may be a selection bias in the present study. Generally, 
esophagectomy itself has a $30 \%-40 \%$ morbidity rate and $1 \%$ $2 \%$ mortality rate. Surgeons thus avoid performing esophagectomy for certain patients, particularly elderly patients. The impact of postoperative pneumonia may, therefore, have been artificially emphasized in this cohort. Third, there was a time bias in this study, as the data were collected between 2008 and 2018. Surgical procedures and perioperative care might have changed over this period. Considering these limitations, the current results should be validated by another study.

In conclusion, the present study confirms that the development of postoperative pneumonia is a risk factor for OS in patients who undergo esophagectomy for esophageal cancer. To improve these patients' survival, it is necessary to prevent them from developing postoperative pneumonia following esophagectomy.

\section{Conflicts of Interest}

The Authors declare no competing interests in association with the present study.

\section{Authors' Contributions}

Ayako Tamagawa and Toru Aoyama made substantial contributions to conception and design. Ayako Tamagawa, Toru Aoyama, Hiroshi Tamahawa, Mihwa Ju, Keisuke Komori, Yukio Maezawa, Kazuki Kano, Keisuke Kazama, Masaaki Murakawa, Yosuke Atsumi, Sho Sawazaki, Kentaro Hara, Masakatsu Numata, Tsutomu Sato, Norio Yukawa, Manetaka Masuda And Yasushi Rino made substantial contributions to acquisition of data, or analysis and interpretation of data and have been involved in drafting the manuscript or revising it critically for important intellectual content.

Ayako Tamagawa and Toru Aoyama have given final approval of the version to be published. Each author should have participated sufficiently in the work to take public responsibility for appropriate portions of the content; and agreed to be accountable for all aspects of the work in ensuring that questions related to the accuracy or integrity of any part of the work are appropriately investigated and resolved. All Authors read and approved the final manuscript.

\section{References}

1 Torre LA, Bray F, Siegel RL, Ferlay J, Lortet-Tieulent J and Jemal A: Global cancer statistics, 2012. CA Cancer J Clin 65: 87-108, 2015. PMID: 25651787. DOI: 10.3322/caac.21262

2 NCCN: NCCN Clinical Practice Guidelines in Oncology. Available at: https://www.nccn.org/professionals/physician _gls/default.aspx

3 Lordick F, Mariette C, Haustermans K, Obermannová R, Arnold D: ESMO Guidelines Committee. Oesophageal cancer: ESMO Clinical Practice Guidelines for diagnosis, treatment and followup. Ann Oncol 27: v50-v57, 2016. PMID: 27664261. DOI: 10.1093/annonc/mdw329

4 Hayashi T, Yoshikawa T, Aoyama T, Hasegawa S, Yamada T, Tsuchida K, Fujikawa H, Sato T, Ogata T, Cho H, Oshima T, Rino $\mathrm{Y}$ and Masuda M: Impact of infectious complications on gastric cancer recurrence. Gastric Cancer 18: 368-374, 2015. PMID: 24634097. DOI: 10.1007/s10120-014-0361-3

5 Aoyama T, Murakawa M, Katayama Y, Yamaoku K, Kanazawa A, Higuchi A, Shiozawa M, Morimoto M, Yoshikawa T, Yamamoto $\mathrm{N}$, Rino Y, Masuda M and Morinaga S: Impact of postoperative complications on survival and recurrence in pancreatic cancer. Anticancer Res 35: 2401-2409, 2015. PMID: 25862906.

6 Aoyama T, Oba K, Honda M, Sadahiro S, Hamada C, Mayanagi S, Kanda M, Maeda H, Kashiwabara K, Sakamoto J, Saji S and Yoshikawa T: Impact of postoperative complications on the colorectal cancer survival and recurrence: analyses of pooled individual patients' data from three large phase III randomized trials. Cancer Med 6: 1573-1580, 2017. PMID: 28639738. DOI: 10.1002/cam4.1126

7 Kano K, Aoyama T, Yoshikawa T, Maezawa Y, Nakajima T, Hayashi T, Yamada T,Sato T, Oshima T, Rino Y, Masuda M, Cho $\mathrm{H}$ and Ogata $\mathrm{T}$ : The negative survival impact of infectious complications after surgery is canceled out by the response of neoadjuvant chemotherapy in patients with esophageal cancer. Ann Surg Oncol 25: 2034-2043, 2018. PMID: 29748890. DOI: 10.1245/s 10434-018-6504-8

8 Lerut T, Moons J, Coosemans W, Van Raemdonck D, De Leyn P, Decaluwé H, Decker $G$ and Nafteux P: Postoperative complications after transthoracic esophagectomy for cancer of the esophagus and gastroesophageal junction are correlated with early cancer recurrence: role of systematic grading of complications using the modified Clavien classification. Ann Surg 250: 798-807, 2009. PMID: 19809297. DOI: 10.1097/ SLA.0b013e3181bdd5a8

9 Ancona E, Cagol M, Epifani M, Cavallin F, Zaninotto G, Castoro C, Alfieri R and Ruol A: Surgical complications do not affect longterm survival after esophagectomy for carcinoma of the thoracic esophagus and cardia. J Am Coll Surg 203: 661-669, 2006. PMID: 17084327. DOI: 10.1016/j.jamcollsurg. 2006.07.017

10 Ferri LE, Law S, Wong KH, Kwok KF and Wong J: The influence of technical complications on postoperative outcome and survival after esophagectomy. Ann Surg Oncol 13: 557-564, 2006. PMID: 16485146. DOI: 10.1245/ASO .2006.04.040

11 Rizk NP, Bach PB, Schrag D, Bains MS, Turnbull AD, Karpeh M, Brennan MF and Rusch VW: The impact of complications on outcomes after resection for esophageal and gastroesophageal junction carcinoma. J Am Coll Surg 198: 42-50, 2004. PMID: 14698310. DOI: 10.1016/j.jamcollsurg.2003.08.007

12 Lindner K, Fritz M, Haane C, Senninger N, Palmes D and Hummel R: Postoperative complications do not affect long-term outcome in esophageal cancer patients. World J Surg 38: 26522661, 2014. PMID: 24867467. DOI: 10.1007/s00268-014-2590-3

13 D'Annoville T, D'Journo XB, Trousse D, Brioude G, Dahan L, Seitz JF, Doddoli C and Thomas PA: Respiratory complications after oesophagectomy for cancer do not affect disease-free survival. Eur J Cardiothorac Surg 41: e66-73, 2012. PMID: 22408043. DOI: $10.1093 /$ ejcts/ezs080

14 Sobin LH, Gospodarowicz MK and Wittekind C: International Union Against Cancer (UICC) TNM classification of malignant tumors. 7. New York: Wiley-Liss; 2010.

15 Katsura M, Kuriyama A, Takeshima T, Fukuhara $S$ and Furukawa TA: Preoperative inspiratory muscle training for postoperative pulmonary complications in adults undergoing cardiac and major abdominal surgery. Cochrane Database Syst Rev 2015(10): CD010356, 2015. PMID: 26436600. DOI: 10.1002/14651858.CD010356.pub2 
16 Gomes NM, Martinez BP, Reis HF and Carvalho VO: Pre- and postoperative inspiratory muscle training in patients undergoing cardiac surgery: systematic review and meta-analysis. Clin Rehabil 31: 454-464, 2016. PMID: 27154820. DOI: 10.1177/ 0269215516648754

17 Dettling DS, van der Schaaf M, Blom RL, Nollet F, Busch OR and van Berge Henegouwen MI: Feasibility and effectiveness of pre-operative inspiratory muscle training in patients undergoing oesophagectomy: a pilot study. Physiother Res Int 13: 16-26, 2013. PMID: 22489016. DOI: $10.1002 /$ pri. 1524

18 World Medical Association: Declaration of Helsinki. Law Med Health Care. Fall-Winter 19: 264-265, 1991. PMID: 11642954.

19 Kataoka K, Takeuchi H, Mizusawa J, Igaki H, Ozawa S, Abe T, Nakamura K, Kato K, Ando N and Kitagawa Y: Prognostic impact of postoperative morbidity after esophagectomy for esophageal cancer: Exploratory analysis of JCOG9907. Ann Surg 265: 1152-1157, 2017. PMID: 27280509. DOI: 10.1097/ SLA.0000000000001828

20 Booka E, Takeuchi H, Nishi T, Matsuda S, Kaburagi T, Fukuda K, Nakamura R, Takahashi T, Wada N, Kawakubo H, Omori T and Kitagawa Y: The impact of postoperative complications on survivals after esophagectomy for esophageal cancer. Medicine (Baltimore) 94: e1369, 2015. PMID: 26287423. DOI: 10.1097/ MD.0000000000001369
21 Asaka S, Shimakawa T, Yamaguchi K, Katsube T, Usui T, Yokomizo H, Shiozawa $S$ and Naritaka Y: Postoperative pneumonia after esophagectomy and systemic inflammatory. response syndrome. Anticancer Res 39: 979-985, 2019. PMID: 30711984. DOI: 10.21873/anticanres.13202

22 Goldfarb Y, Sorski L, Benish M, Levi B, Melamed R and BenEliyahu S: Improving postoperative immune status and resistance to cancer metastasis: a combined perioperative approach of immunostimulation and prevention of excessive surgical stress responses. Ann Surg 253: 798-810, 2011. PMID: 21475023. DOI: $10.1097 /$ SLA.0b013e318211d7b5

23 Dunn GP, Old LJ and Schreiber RD: The immunobiology of cancer immunosurveillance and immunoediting. Immunity 21 : 137-148, 2004. PMID: 15308095. DOI: 10.1016/j.immuni. 2004.07.017

Received April 11, 2019

Revised April 26, 2019

Accepted April 30, 2019 